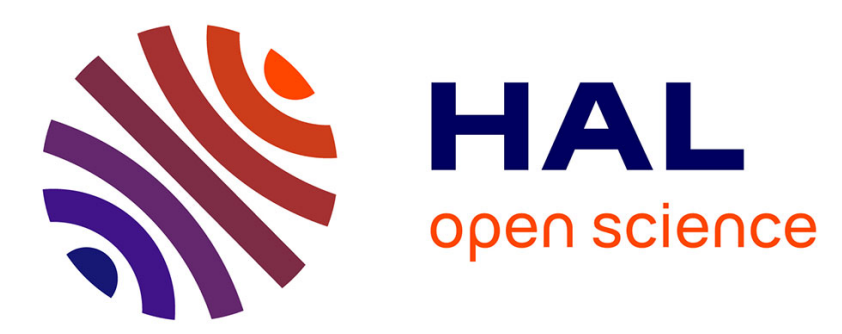

\title{
Small-angle X-ray scattering study of the microstructure of highly porous silicon
}

\author{
A. Naudon, P. Goudeau, A. Halimaoui, G. Bomchil
}

\section{To cite this version:}

A. Naudon, P. Goudeau, A. Halimaoui, G. Bomchil. Small-angle X-ray scattering study of the microstructure of highly porous silicon. Journal de Physique IV Proceedings, 1993, 03 (C8), pp.C8-349C8-352. 10.1051/jp4:1993871 . jpa-00252302

\section{HAL Id: jpa-00252302 https://hal.science/jpa-00252302}

Submitted on 1 Jan 1993

HAL is a multi-disciplinary open access archive for the deposit and dissemination of scientific research documents, whether they are published or not. The documents may come from teaching and research institutions in France or abroad, or from public or private research centers.
L'archive ouverte pluridisciplinaire HAL, est destinée au dépôt et à la diffusion de documents scientifiques de niveau recherche, publiés ou non, émanant des établissements d'enseignement et de recherche français ou étrangers, des laboratoires publics ou privés. 


\title{
Small-angle X-ray scattering study of the microstructure of highly porous silicon
}

\author{
A. NAUDON, Ph. GOUDEAU, A. HALIMAOUI* and G. BOMCHIL ${ }^{*}$ \\ Laboratoire de Métallurgie Physique, URA 131 du CNRS, Université de Poitiers, 40 avenue du Recteur \\ Pineau, 86022 Poitiers cedex, France \\ *France Télécom, CNET, BP. 98, 38243 Meylan cedex, France
}

\begin{abstract}
Small-Angle X-ray Scattering is well suited to the study of porous silicon microstructure since the pore radii range $(2-10 \mathrm{~nm})$ corresponds to the small-angle scattering range $(1-100 \mathrm{~nm})$. In all the studies realized till now, the porous silicon layers were always supported by the substrate. Recently, it has been possible to detach the porous silicon layer from the substrate. We performed small-angle X-ray scattering measurements, on such P-type samples, at a synchrotron radiation source. Close to the origin, the scattering pattern shows an anisotropic behaviour when tilting the sample surface with respect to the X-ray beam. This anisotropy is different from the one observed previously in the case of $\mathrm{P}^{+}$samples.
\end{abstract}

\section{INTRODUCTION}

Porous silicon (PS) layers are generally formed by an electrochemical dissolution of monocrystalline silicon in concentrated hydrofluoric acid solutions. High porosity can be obtained, leading then to a silicon microstructure which consists of a network of extremely small pores (1). For porosity greater than $80 \%$, a photoluminescence phenomenum appears in the visible range which can be attributed to quantum size effects (2).

As the size of the pores in PS layers lies in the range where small-angle X-ray scattering (SAXS) may be used, this technique is well adapted to the study of PS microstructure. Synchrotron facilities can be used to get information in the angular range very close to the angular origin and also, using a two-dimensional detector, to study anisotropic scattering.

The microstructure dependence of the PS with the doping level in p-type silicon has already been studied by SAXS $(3,4)$. In lightly doped p-type silicon $(P)$, the scattering pattern is isotropic while in heavily doped $\mathrm{p}$-type silicon $\left(\mathrm{P}^{+}\right)$, the PS structure consists of many long voids (rod-like) running perpendicular to the silicon surface, with small "buds" on their sides. Furthermore, a microstructural study of high-porosity PS layers formed on lightly P-doped wafers has been performed by SAXS (5). When the porosity is increased from $55 \%$ to $85 \%$, there is a continuous modification in the shape of the scattering profiles. These are characteristic of an isotropic threedimensional structure.

In our previous studies, the PS layers samples consisted of a porous layer less than $10 \mu \mathrm{m}$ thick on the surface of a silicon wafer. In order to minimize the X-ray absorption in the transmission mode, and thus to get a good signal to background ratio, the wafers were chemically thinned down from $300 \mu \mathrm{m}$ to a uniform thickness of $100 \mu \mathrm{m}$ prior to porous silicon formation. Recently, a new PS preparation method allowed to detach PS layers as thick as $40 \mu \mathrm{m}$, having a high porosity (till 74\%) from the silicon substrate.

Here, we present SAXS measurements on these new samples. For the reasons mentioned above, the experiments have been performed at the French synchrotron facilities, Laboratoire pour l'Utilisation du Rayonnement Electromagnetique (LURE), Orsay, France. The influence of the tilt of the sample surface with respect to the direction of the direct beam, on the small angle scattering has been studied using a one-dimensional detector for quantitative analysis, and a imaging plate system (2D pattern) for qualitative analysis. 


\section{EXPERIMENTAL}

\section{Sample preparation}

The p-type Si substrates used were (100) oriented, boron doped with a resistivity of $1 \Omega \mathrm{cm}$. PS layers were formed by electrochemical anodisation in a hydrofluoric (HF) acid solution at constant current density. The film thickness and porosity were always determined on separate samples by gravimetric measurements. After PS formation, the PS layers were detached from the substrate by electropolishing. Details concerning sample preparation can be found in ref. (6). Three samples having a porosity of 57,66 and $74 \%$ and a thickness of about $41,44.5$ and $41 \mu \mathrm{m}$, respectively, have been prepared.

\section{$\underline{\text { SAXS experiment }}$}

We use the synchrotron facility available at LURE, where the X-ray source provide a very intense monochromatic beam at the D22 station. The experimental set-up has been described elsewhere (7). Experiments were realized with a pinhole collimated beam (cross section $\leq 1 \mathrm{~mm}^{2}$ ). Data were collected with a linear detector for quantitative analysis, and an imaging plate, now available at LURE, for qualitative interpretation. Imaging Plate (IP) is a new type of X-ray area detector. This system is based on photostimulable phosphor which can temporarily store an X-ray image (8). The excellent performance of the IP as an integrating X-ray area detector is well suited to $\mathrm{X}$-ray scattering experiments using synchrotron radiation. The scattered intensities are recorded as a function of the scattering vector $q=4 \pi \sin \theta / \lambda, 2 \theta$ being the scattering angle and $\lambda$, the $X$ ray wavelength $(1.5418 \AA)$. We chose a sample-detector distance $D=800 \mathrm{~mm}$ in order to get information in the low $\mathrm{q}$ range values; the minimum $\mathrm{q}$ value is $\mathrm{q}_{\mathrm{m}}=0.01 \AA^{-1}$. The anisotropic character was observed by rotation $(\alpha)$ of the sample surface around an axis perpendicular to the $\mathrm{X}$-ray beam as illustrated in fig. 1 . The curves were corrected for sample absorption and incidentbeam intensity in order to obtain intensities on an absolute scale (7).

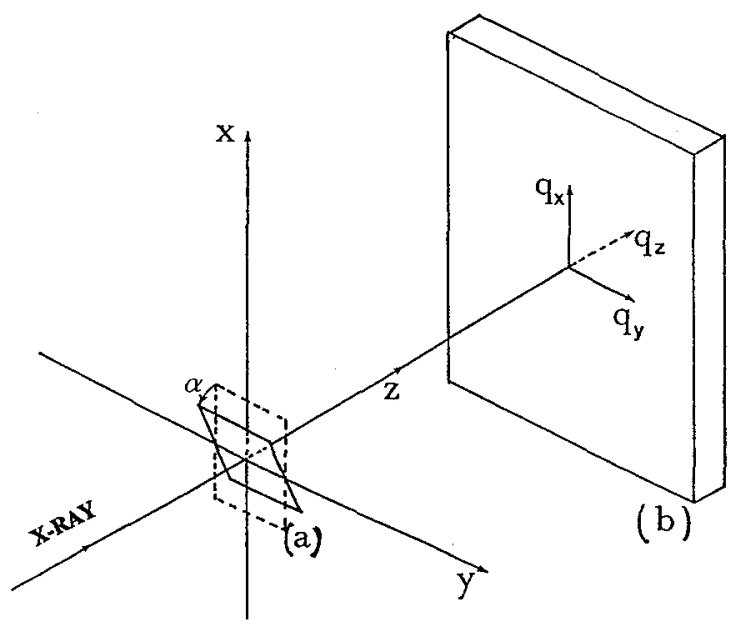

Fig. 1 : Spectrometer geometry used for the tilting procedure showing the relationship between the coordinate system chosen for (a) the surface of the sample and (b) the detector plan.

\section{$\underline{\text { SAXS analysis }}$}

The scattering volume consists of only two types of phases: silicon crystallites with a constant electronic density $\rho_{\mathrm{s}}=0.7 \mathrm{e} \AA^{-3}$ and empty pores with $\rho_{\mathrm{p}}=0$. The scattering curves resulting from such a contrast contain information on the pores in the PS layer.

Two $q$ ranges have to be considered to extract structural parameters: (i) in the small $q$ range (related to particle volume), the Guinier approximation (9) allows the radius of gyration Rg to be calculated, (ii) at the largest q values (related to the particle surface), the generalized Porod law (10) can be used, I(q) $\propto q^{-p}$. When the surface is smooth and the boundaries between the two regions sharp, $\mathrm{p}=4$. 
When the scattering intensity $\mathrm{i}(\mathrm{q})$ is isotropic, one can determine the total scattered integrated intensity $Q_{0}^{\prime}$ within limits $q_{1}=210^{-3} \AA^{-1}$ and $q_{2}=0.7 \AA^{-1}$. it gives a value close to the one of the invariant $\mathrm{Q}_{\mathrm{O}}$ given by (10)

$$
\mathrm{Q}_{\mathrm{O}}=1 /\left(2 \pi^{2}\right) \int_{0}^{\infty} \mathrm{q}^{2} \mathrm{i}(\mathrm{q}) \mathrm{dq}
$$

Let us note that the contribution between the angular origin and $\mathrm{q}_{1}$ is always small.

In porous solids, the two-phase approximation can be used and the invariant is then given by the following formula

where $c$ is the porosity.

$$
\mathrm{Q}_{\mathrm{O}}=\mathrm{c}(1-\mathrm{c}) \rho_{\mathrm{s}}^{2}
$$

\section{RESULTS AND DISCUSSION}

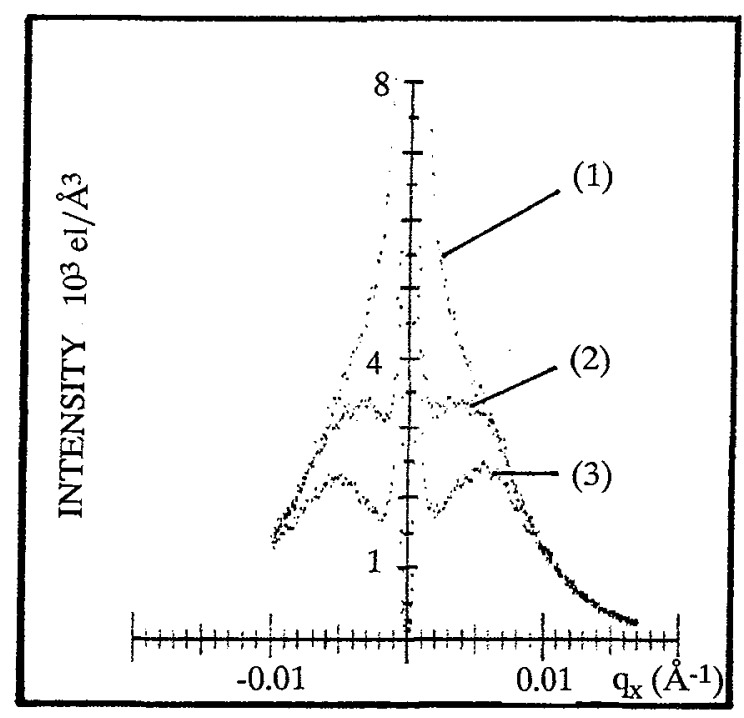

Figure 2 : Influence of the tilting angle on the SAXS profile measured for the $\mathrm{P}$ sample having a porosity of $74 \%$. (1) $\alpha=0^{\circ}, \quad$ (2) $\alpha=30^{\circ}$, (3) $\alpha=45^{\circ}$.

With the one-dimensional detector along the $\mathrm{q}_{\mathrm{x}}$ axis, the influence of the tilting angle $\alpha$ on the SAS curves obtained for the $\mathrm{P}$ sample having a porosity of $74 \%$ is shown in Fig. 2 . The intensity decreases and a maximum in intensity appears as the tilt angle increases. This behaviour is also observed for the two other samples. Nevertheless, the maximum in intensity is more visible when the porosity is higher. this maximum is probably linked with the interference between pores. The correlation length between pores, deduced from the maximum position $q_{m}=0.054 \AA^{-1}$, is equal to $\Lambda=2 \pi / \mathrm{q}_{\mathrm{m}}=115 \AA$.

In the small $\mathrm{q}$ range, an estimation of the pore size is obtained using the Guinier's approximation. The radius of gyration increases from 17 to $22 \AA$ as the porosity increases from 57 to $74 \%$. For all the samples, the $\mathrm{Rg}$ value slightly decreases (from 22 to $19 \AA$ for the sample having a porosity of $74 \%$ ) as the tilting angle increases from 0 to $45^{\circ}$.

The most important fact to be seen in this Fig. 2 is that the scattering profile in the Porod region $\left(\mathrm{q}>0.01 \AA^{-1}\right)$ is not modified when tilting the sample with respect to the $\mathrm{X}$-ray beam and the slope $p$ is equal to -3.50 . This asymptotic behaviour may be due to the roughness of the interface pore matter (11). The scattering law is then expressed as $q^{-(3+\alpha)}$ with $0<\alpha<1, \alpha$ being equal to 0.5 most of the time.

The experimental integrated intensity $\mathrm{Q}_{\mathrm{o}}$ ' determined using eq.1 is similar, for all the samples, to the theoretical one calculated with eq.2. This value slightly decreases (about $6 \%$ ) as the tilt angle increases. Nevertheless, one may assume that the main contribution to the $Q_{0}$ ' value provides from the large $\mathrm{q}$ range $\left(\mathrm{q}>0.01 \AA^{-1}\right)$. Thus, the anisotropic behaviour observed at small 
$\mathrm{q}\left(\mathrm{q}<0.01 \AA^{-1}\right)$ concerns a few large pores which contribution to the total porosity is weak.

The $2 \mathrm{D}$ scattering pattern obtained for the sample having a porosity of $74 \%$ with a tilt angle equal to $45^{\circ}$, is shown in fig. 3. This pattern is different from the one obtained in the case of heavily doped $\mathrm{P}$-type silicon $\left(\mathrm{P}^{+}\right)$. In $\mathrm{P}^{+}$samples, the structure consisted of many long voids (rodlike) running perpendicular to the silicon surface, with small buds on their sides.

Here, two types of contribution to the SAS curves, depending to the q range considered, have to be distinguished:

(i) at small $\mathrm{q}\left(<0.01 \AA^{-1}\right)$, the contribution of large pores perpendicularly oriented to the sample surface, is predominant

(ii) at large $\mathrm{q}\left(>0.01 \AA^{-1}\right)$, the scattering is due to small desoriented pores $(\operatorname{Rg}=22 \AA)$ arranged in a spatially isotropic manner $(\Lambda=115 \AA)$. The tilting procedure, in this case, allows us to separate both contributions in the SAS curves.

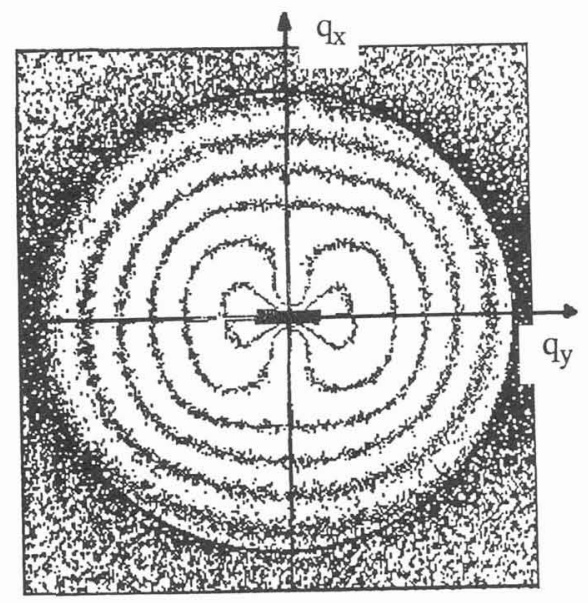

Figure 3. Contour map of the anisotropic scattering intensity of the p-type sample having a porosity of $74 \%$. The tilting angle is equal to $45^{\circ}$ and the disturbance in the middle is due to the beam stop.

\section{ACKNOWLEDGMENTS}

We wish to thank the technical staff of LURE-DCI for providing the synchrotron beam and for assistance with the experiments.

\section{REFERENCES}

[1] R.L. Smith and S.D. Collins, J. Appl. Phys., 71 (1992) R1.

[2] L.T. Canham, Appl. Phys. Lett., 57 (1990) 1046.

[3] P. Goudeau, A. Naudon, G. Bomchil and R. Herino, J. Appl. Phys., 66 (1989) 625.

[4] V. Vezin, Ph. Goudeau, A. Naudon, A. Herino and G. Bomchil, J. Appl. Cryst. 24 (1991) 581.

[5] V. Vezin, P. Goudeau, A. Naudon, A. Halimaoui and G. Bomchil, Appl. Phys. Lett., 60 (1992) 2625.

[6] I. Sagnes, A. Halimaoui, G. Vincent and P.A. Badoz, Appl. Phys. Lett., 62 (1993) 1155.

[7] Ph. Goudeau, A. Naudon, J.-M. Welter, J. Appl. Cryst., 23 (1990) 266.

[8] Y. Amemiya, Synchrotron Radiation News, 3 (1990) 21.

[9] A. Guinier and G. Fournet, Small-Angle Scattering of X-ray. New York: Wiley (1955).

[10] G. Porod, in Small-Angle X-ray Scattering, edited by H. Brumberger (Gordon and Breach, New York, 1967), p. 1.

[11] P.Z. Wong and A.J. Bray, Phys. Rev. Lett., 59 (1987) 1057. 